\title{
Rendimento de carcaça e composição química da carne da perdiz nativa (Rhynchotus rufescens)
}

\author{
Carcass income and chemical composition of the native partridge \\ (Rhynchotus rufescens - Tinamiformes) meat
}

\author{
Maria Estela Gaglianone Moro ${ }^{1}$ Joji Ariki $^{2}$ Pedro Alves de Souza ${ }^{2}$ \\ Hirasilva Barbosa Alves de Souza ${ }^{2}$ Vera Maria Barbosa de Moraes $^{2}$ \\ Flávia Carolina Vargas ${ }^{3}$
}

\section{RESUMO}

A composição química da carne e o rendimento de carcaça de perdizes (Rhynchotus rufescens) adultas, com 12 meses, criadas em cativeiro com rações balanceadas, foram determinadas neste trabalho. Para rendimento de carcaça, após o abate e evisceração, foram feitos dois cortes: peito e coxa+sobrecoxa+dorso. Para análise química, foram retiradas três amostras de cada corte para determinação da composição centesimal da umidade, proteínas totais, lipídeos totais, cinzas e colesterol. Os valores observados mostraram um rendimento médio de carcaça de $74,4 \%$ com $36,6 \%$ de carne de peito. Os componentes químicos apresentaram para os cortes de coxasobrecoxa e peito, respectivamente, umidade 62,4 e 55,9\%; proteínas 25,2 e 29,1\%; lipídeos 1,6 e 5,6\%; cinzas 1,4 e $1,2 \%$ e colesterol 234 e $70 \mathrm{mg} / 100 \mathrm{~g}$. O excelente rendimento de carcaça, somado à composição química de sua carne, mostra o potencial desta espécie para a produção de carnes especiais.

Palavras-chave: carne, composição química, perdiz, rendimento de carcaça.

\section{ABSTRACT}

The composition of the meat and the carcass income of 12 months adult partridges (Rhynchotus rufescens), raised in captivity with balanced rations were established in this work. For carcass income, two cuts were made: thigh+ over-thigh + back and chest. For the chemical analysis three samples of each cut were removed to determinate the centesimal composition of the moisture, total proteins, total lipids, ashes and cholesterol. The observed values showed a medium income

\begin{abstract}
of carcass of $74.4 \%$ with $36.6 \%$ of chest meat. The chemical components presented for the cuts of thigh + over-thigh + back and chest respectively, were: moisture 62.4 and $55.9 \%$; proteins 25.2 and 29.1\%; lipids 1.6 and 5.6\%; ashes 1.4 and $1.2 \%$, and cholesterol 234 and $70 \mathrm{mg} / 100 \mathrm{~g}$. The excellent carcass income added to the chemical composition of this meat show the potential of this species for the production of special meats.
\end{abstract}

Key words: chemical composition, meat, partridge, yield carcass.

\section{INTRODUÇÃO}

A carne de animais silvestres é uma alternativa alimentar em muitos países, inclusive nos desenvolvidos. Sabe-se que, em algumas regiões do mundo, a carne de caça constitui a principal fonte de proteína animal para o consumo humano.

No Brasil, a ave nativa Rhynchotus rufescens, denominada popularmente de perdiz ou perdigão no sul do país, por ter grande potencial, tem despertado interesse para sua criação em cativeiro, levando a possibilidade da utilização de sua carne como fonte protéica alternativa. $\mathrm{O}$ sucesso dos criadouros trariam condições de se utilizar aves para repovoamento e fornecimento de carne para o mercado consumidor, diminuindo desta forma, a pressão da caça predatória.

As perdizes adultas pesam em média $750 \mathrm{~g}$, sendo as fêmeas mais pesadas que os machos podendo alguns indivíduos alcançar peso superior a $1000 \mathrm{~g}$

\footnotetext{
${ }^{1}$ Departamento de Zootecnia da Faculdade de Zootecnia e Engenharia de Alimentos - Universidade de São Paulo - Campus de Pirassununga, São Paulo. Caixa Postal 23- CEP. 13635-900 - Pirassununga, SP, Brasil - E-mail: estemoro@usp.br

${ }^{2}$ Faculdade de Ciências Agrárias e Veterinárias - Universidade Estadual Paulista - Rod. Carlos Tonnani, km 5, Jaboticabal, SP, Brasil.

${ }^{3}$ Curso de Pós-graduação da Faculdade de Zootecnia e Engenharia de Alimentos - USP - Campus de Pirassununga, SP, Brasil.
} 
(WEEKS, 1973). Nos estudos feitos em cativeiro, MORO (1991) obteve peso máximo de $900 \mathrm{~g}$ e $710 \mathrm{~g}$, para fêmeas e machos adultos. CARNIO (1993), através de análise do desenvolvimento ponderal, observou, à $10^{\mathrm{a}}$ semana de idade, pesos de $389,16 \mathrm{~g}$ e $500,83 \mathrm{~g}$ para os sexos acima referidos.

O conhecimento de dados sobre a qualidade, a composição e o rendimento de carcaça da perdiz são importantes no estudo da viabilidade comercial para o aproveitamento de uma espécie, além de fornecer subsídios para o seu aproveitamento tecnológico. O cálculo do rendimento de carcaça estabelece uma relação entre peso vivo e peso final da carcaça de um animal após seu abate e processamento. Mas, quando se fala sobre rendimento de carcaça de espécies semidomesticadas ou ainda silvestres, poucos são os dados disponíveis na literatura para embasar discussões e comparações.

Pesquisas desenvolvidas no Canadá com um tinamídeo (Nothoprocta perdicaria) nativo do Chile, demonstraram a potencialidade desta ave para a produção comercial de carne. AGGREY et al. (1992) trabalharam com 28 aves desta espécie em cativeiro, concluindo que, apesar de apresentarem um tempo maior para alcançar o peso e a idade de mercado quando comparadas com aves industriais, chegam à $16^{\mathrm{a}}$ semana, após abate e sem pele, com peso médio de $455,8 \mathrm{~g}$ e rendimento de $76,8 \%$. Os músculos do peito e da perna são compostos de carne branca translúcida e o rendimento de carcaça foi comparável ao de frangos e perus comerciais. A carne do peito pesou $138 \mathrm{~g}$ e foi de $40,7 \%$ do peso eviscerado, sendo portanto, superior ao rendimento de frangos, perus e codornas.

$\mathrm{Na}$ França, estudos desenvolvidos com a galinha D'Angola, demonstraram alto grau de sofisticação e pesquisas intensivas com programas de cruzamentos, visando ao melhoramento desta espécie, mostrando que é possível obter carne de excelente qualidade, com um rendimento de carcaça ao redor de $70 \%$ e proporção da carne de peito em relação ao peso corporal em torno de $19 \%$, com baixo custo de produção (SAUVER \& PLOUZEAU, 1993).

A avaliação do potencial para a produção de carne do tinamídeo Nothoprocta perdicaria, que ocorre no Chile foi apresentada por KERMODE et al., (1995), demonstrando que uma ave desta espécie com $450 \mathrm{~g}$ possui um rendimento de $77 \%$ com $41 \%$ deste rendimento como peso de carne de peito.

No mercado das carnes exóticas, o jacaré e o avestruz tem despertado grande interesse quanto ao seu potencial para a produção de carne. As duas espécies mostram que seu rendimento de carcaça tem grande dependência do sexo e da idade de abate. Os jacarés estudados por ROMANELLI (1995) mostraram uma variação no rendimento de 59,4 a 62,5\% em função do tamanho corporal. Já os avestruzes de 12 meses de vida, com 100kg de peso vivo, conferem um rendimento de carcaça ao redor de 60\% (SHANAWANY, 1996).

As diferenças taxonômicas e biométricas dificultam a precisão das comparações dos dados de rendimento de carcaça entre os animais de diferentes espécies. Mas, para os componentes químicos do músculo, a comparação se torna mais fácil, pela existência de metodologia padronizada entre os laboratórios (ROMANELLI, 1995). A tabela 1 mostra a composição química aproximada da carne de algumas espécies domésticas ou não.

O teor de colesterol das carnes vermelhas é inferior ao das carnes brancas, segundo RODRIGUES (1994). Verifica-se que as carnes bovina, suína e ovina não apresentam valores de colesterol significativamente mais elevados do que outras como frango, peru ou peixe. A carne magra de bovinos e suínos contém $75 \mathrm{mg}$ e $60 \mathrm{mg}$ de colesterol/100g, respectivamente, e a coxa de frango sem pele, contém $91 \mathrm{mg} / 100 \mathrm{~g}$. Estes dados, segundo o autor, representam, nesta ordem, 25, 20 e $30 \%$ do valor máximo recomendado para consumo, pela American Heart Association (AHA), o qual é de 300mg de colesterol por dia.

Na carne fresca do jacaré brasileiro, ROMANELLI (1995) encontrou um teor médio de colesterol de 63,5 a 85,5mg/100g. Os valores nutritivos da carne do avestruz para cada $100 \mathrm{~g}$, foram descritos por SHANAWANY (1996) sendo de 2,0g de gordura, $58 \mathrm{mg}$ de colesterol, $21,9 \mathrm{~g}$ de proteína, $5,2 \mathrm{mg}$ de cálcio e $114 \mathrm{cal}$ de energia. Estes valores conferem a este tipo de carne, características de um alimento altamente protéico com baixos níveis de gordura e colesterol.

Este trabalho teve como objetivo realizar observações sobre o rendimento da carcaça e composição da carne da perdiz nativa criada em cativeiro.

\section{MATERIAL E MÉTODOS}

As aves da espécie Rhynchotus rufescens utilizadas neste estudo, foram criadas em galpão de alvenaria recebendo ração balanceada elaborada a partir das recomendações do NATIONAL RESEARCH COUNCIL (NRC, 1994) para faisões (Phasianus colchicus), sendo apresentada na tabela 2 .

Para o cálculo do rendimento de carcaça e cortes, foram abatidas 10 aves adultas com idade média de 56 semanas, com o intuito de apresentar dados iniciais de rendimento e composição da carcaça, para futuros experimentos nesta área. As aves foram pesadas 
Tabela 1 - Composição centesimal aproximada da carne de algumas espécies de diferentes animais.

\begin{tabular}{llllll}
\hline Espécie animal & Umidade & Proteína & Lipídios & Cinzas & Referência \\
\hline Jacaré americano & $73-77$ & $21-23$ & $1-1,5$ & 1,3 & MOODY et al. (1980) \\
Coelho & $60-73$ & $18-19$ & $8-11$ & - & RAO et al. (1978) \\
Boi & 76 & 21,5 & 10,5 & 1 & TURGUT (1984) \\
Frango & 74,9 & 20,7 & 3,7 & 0,7 & WHITING \& JEKINS (1981) \\
Rã & $81,5-82,5$ & $16-17,5$ & $0,6-0,8$ & 1 & CORREA (1988) \\
Peru & - & 21,9 & 2,4 & - & SAUVEUR \& PLOZEAU (1993) \\
Galinha D'Angola & - & 23,2 & 2,0 & - & SAUVEUR \& PLOZEAU (1993) \\
Jacaré brasileiro & $75-78$ & 18,5 & $2,5-6$ & 1 & ROMANELLI (1995) \\
\hline
\end{tabular}

Fonte: Adaptado de ROMANELLI (1995)

antes do abate, para o qual foram submetidas a um jejum de 12 horas e sacrificadas por deslocamento cervical. Após retirada da cabeça, pele e penas, vísceras e pés, a carcaça ainda quente, foi pesada em balança eletrônica com precisão de $0,1 \mathrm{~g}$.

Foram feitos, após pesagem da carcaça limpa, dois cortes: do peito (sem pele) e da perna + coxa + dorso + asa, os quais foram pesados separadamente para a análise de sua porcentagem na carcaça total. Através de cálculos matemáticos, foram feitas as porcentagens de rendimento da carcaça e do rendimento do peito em relação à carcaça limpa, e a porcentagem de graxaria em relação ao peso total.

Para a análise dos componentes químicos musculares, retirou-se amostras ao acaso de três aves, dos cortes do peito sem pele e da perna-coxa. A determinação das proteínas totais, umidade, lipídios totais e cinzas, foi feita utilizando-se as metodologias daA.O.A.C., 1984.

Para avaliação dos teores de colesterol total, utilizou-se a metodologia proposta por ROMANELLI (1995). As análises foram processadas no Laboratório do Departamento de Tecnologia da Faculdade de Ciências Agrárias e Veterinárias - UNESP - Jaboticabal.

\section{RESULTADOS E DISCUSSÃO}

Os resultados de rendimento da carcaça, apresentados na tabela 3 , evidenciam que a perdiz nativa possui rendimento similar ou melhor que algumas espécies domésticas ou silvestres, que já são exploradas comercialmente. O trabalho de AGGREY et al., (1992) com um tinamídeo chileno, mostra aves com 16 semanas de idade pesando $455 \mathrm{~g}$ e um rendimento de carcaça de $76,8 \%$. A carne de peito pesou $138 \mathrm{~g}$, perfazendo 40,7\% do peso da carcaça. KERMODE et al., (1995), também trabalharam com este tinamídeo chileno e alcançaram resultados de um rendimento de carcaça de $77 \%$, com $41 \%$ deste rendimento em carne de peito.

Comparativamente, a galinha D'Angola, que é uma das aves que tem merecido, na atualidade, destaque quanto à sua criação para produção de carne, em criações sofisticadas na Europa, obtém um rendimento de carcaça eviscerada de $70 \%$ e carne de peito com 19\% do peso corporal (SAUVER \& PLOUZEAU, 1993). Estes dados comprovam e reforçam os argumentos de que a perdiz, possuindo um rendimento médio de $74,4 \%$ de carcaça e de $36,6 \%$ de carne de peito, sem nenhuma seleção para estas características, é uma espécie que merece a atenção no

Tabela 2 - Níveis de proteína bruta (PB \%) e energia metabolizável (kcalEM/kg) da ração fornecida de acordo com a fase da vida da ave.

\begin{tabular}{|c|c|c|c|c|c|c|c|}
\hline & & \multicolumn{2}{|c|}{ Idades } & \multicolumn{2}{|c|}{ (semanas) } & & \\
\hline \multicolumn{2}{|c|}{$1-4$} & \multicolumn{2}{|c|}{$5-8$} & \multicolumn{2}{|c|}{$9-20$} & \multicolumn{2}{|c|}{$>21$} \\
\hline $\mathrm{PB}$ & EM & PB & EM & PB & EM & $\mathrm{PB}$ & EM \\
\hline 28 & 2800 & 24 & 2800 & 18 & 2700 & 15 & 2800 \\
\hline
\end{tabular}

$\mathrm{PB}=$ Proteína bruta

$\mathrm{EM}=$ Energia metabolizável

Ciência Rural, v.36, n.1, jan-fev, 2006. 
Tabela 3 - Valores de rendimento de carcaça da perdiz (Rhynchotus rufescens).

\begin{tabular}{|c|c|c|c|c|c|c|c|}
\hline Ave & Peso total (g) & Carcaça (g) & $\begin{array}{l}\text { Rendimento } \\
\text { carcaça }(\%)\end{array}$ & Peito (g) & $\begin{array}{c}\text { Rendimento } \\
\text { peito/carcaça } \\
(\%)\end{array}$ & Graxaria* (g) & Graxaria (\%) \\
\hline 1 & 658,9 & 470,6 & 71,4 & 173,6 & 36,9 & 188,3 & 28,6 \\
\hline 2 & 663,5 & 507,1 & 76,4 & 193,7 & 38,2 & 156,4 & 23,6 \\
\hline 3 & 536,9 & 389,0 & 72,4 & 149,7 & 38,5 & 147,9 & 27,5 \\
\hline 4 & 622,4 & 476,0 & 76,5 & 174,0 & 36,5 & 146,4 & 23,5 \\
\hline 5 & 735,7 & 545,2 & 74,1 & 191,2 & 35,1 & 190,5 & 25,9 \\
\hline 6 & 509,0 & 378,1 & 74,3 & 136,1 & 36,0 & 130,9 & 25,7 \\
\hline 7 & 776,4 & 585,0 & 75,3 & 213,3 & 36,5 & 191,4 & 24,6 \\
\hline 8 & 671,5 & 513,6 & 76,5 & 191,8 & 37,3 & 157,9 & 23,5 \\
\hline 9 & 674,5 & 502,3 & 74,5 & 179,2 & 35,7 & 172,3 & 25,5 \\
\hline 10 & 524,0 & 378,3 & 72,2 & 135,7 & 35,9 & 145,7 & 27,8 \\
\hline Média & 637,3 & 474,5 & 74,4 & 173,8 & 36,6 & 162,8 & 25,6 \\
\hline
\end{tabular}

* - Pele, penas, vísceras comestíveis ou não, cabeça, pés.

sentido de ser trabalhada geneticamente, visando melhorar seu rendimento para a produção de carne.

Os valores médios dos componentes químicos da carne da perdiz são apresentados na tabela 4. A associação dos valores de umidade de $62,4 \%$ para a carne do corte perna-coxa e de $55,9 \%$ para o corte do peito (sem pele), com o valor dos lipídios de $1,6 \%$ e $5,6 \%$ para os respectivos cortes, mostra que estes valores são coerentes entre si. Estes resultados são concordantes com Miller et al. (1986) citados por ROMANELLI (1995) que observaram que o aumento de lipídios nos músculos é acompanhado pelo decréscimo de umidade. Os lipídios são o componente químico mais variável dos músculos, pois ele não depende necessariamente do crescimento muscular, e sim da dieta nutricional.

Os valores médios observados para cinzas, 1,4 e $1,2 \%$, para os cortes perna-coxa e peito, são superiores aos de outras espécies de animais pesquisados por diversos autores citados na tabela 1 .

Tabela 4 - Valores médios da composição química da carne da perdiz.

\begin{tabular}{lccccc}
\hline Cortes & $\begin{array}{c}\text { Umidade } \\
(\%)\end{array}$ & $\begin{array}{c}\text { Proteínas } \\
(\%)\end{array}$ & $\begin{array}{c}\text { Lipídios } \\
(\%)\end{array}$ & $\begin{array}{c}\text { Cinzas } \\
(\%)\end{array}$ & $\begin{array}{c}\text { Colesterol } \\
\text { mg 100 }^{-1}\end{array}$ \\
\hline Perna-coxa & 62,4 & 25,2 & 1,6 & 1,4 & 234 \\
Peito sem pele & 55,9 & 29,1 & 5,6 & 1,2 & 70 \\
\hline
\end{tabular}

Segundo MOODY et al. (1980), o teor de cinzas tende a aumentar com o avanço do crescimento animal. Considerando-se que as carcaças analisadas eram de aves adultas, este valor mais alto das cinzas em relação às outras espécies, estaria explicado.

Os teores médios obtidos para a proteína, 25,2 e $29,1 \%$, para os cortes de perna-coxa e peito (sem pele), são superiores quando comparados às outras espécies: rã, 17\% (CORREA, 1988); jacaré, 18,5\% (ROMANELLI, 1995); coelho, 18,5\% (RAO et al., 1978); frango, 20,7\% (WHITING \& JEKINS, 1981); boi, 21,5\% (TURGUT, 1984); peru, 21,9\% e galinha D'Angola, 23,2\% (SAUVER \& PLOUZEAU, 1993).

Os valores médios da concentração de colesterol para os cortes de perna-coxa e peito (sem pele) de $234 \mathrm{mg}$ e $70 \mathrm{mg} / 100 \mathrm{~g}$,respectivamente, comparados aos de outras espécies mostram que o teor de colesterol do corte perna-coxa foi muito maior, enquanto a taxa encontrada no corte de peito foi comparável ao da carne magra de bovinos e suínos, 75 e $60 \mathrm{mg} / 100 \mathrm{~g}$, inferior à carne de peito de frango 80,2mg/ 100g (RODRIGUES, 1994), situando-se na média dos valores observados por ROMANELLI (1995) para jacarés que foi de $63,5 \mathrm{a} 85,5 \mathrm{mg} / 100 \mathrm{~g}$, e superior ao da carne de avestruzes, 58mg/100g (SHANAWANY, 1996).

Analisando-se de forma geral, os valores observados na composição da carne do peito da perdiz evidenciam que esta carne é do tipo exigido atualmente pelo mercado consumidor, nutritiva, de excelente qualidade e com níveis normais de colesterol 


\section{CONCLUSÕES}

O excelente rendimento de carcaça, 74,4\% em média, com $36,6 \%$ deste rendimento em carne de peito, mostra o potencial desta espécie para a produção de carnes especiais. A ótima qualidade de sua carne, conferida através dos resultados da sua composição química, somada ao bom rendimento de carcaça, reforça a necessidade de trabalhos de seleção e melhoramento da perdiz nativa visando incrementar seus índices produtivos.

\section{AGRADECIMENTOS E APRESENTAÇÃO}

Trabalho apresentado na XXXV Reunião Anual da Sociedade Brasileira de Zootecnia, julho de 1998, Botucatu, SP, Brasil. Anais... p.513.

\section{REFERÊNCIAS}

AGGREY, S.E. et al. The partridge tinamou for commercial meat production: preliminary evaluation. In: WORLD'S POULTRY CONGRESS, 19., 1992, Amsterdam: WPSA ,

1992 Anais... Amsterdan, 1992. p.360.

ASSOCIATION OF OFFICIAL ANALYTICAL CHEMISTS, Official methods of analytical chemists. 14.ed. Arlington, 1984. 1141p.

CARNIO, A. Análise de algumas características produtivas e reprodutivas da Perdiz - Rhynchotus rufescens. 1993. 58f. Monografia (Curso de Graduação em Zootecnia) - Faculdade de Ciências Agrárias e Veterinárias, Universidade Estadual Paulista, Jaboticabal.

CORRÊA, A.L.S. Avaliação composicional de diversas espécies de rãs e efeitos de armazenamento a $\mathbf{- 1 8 0 C}$, sobre frações protéicas e lipídicas do músculo de rãs touro (Rana catesbiana). 1988. 132f. Dissertação (Mestrado em Engenharia de Alimentos) - Curso de Pós-graduação em Engenharia de Alimentos, Universidade de Campinas.

KERMODE, D. et al. Evaluation of two commercially available diets for partridge tinamou meat production. In: [ANNUAL MEETING. POULTRY SCIENCE ASSOCIATION], 84; 1995, Edmonton, Alberta, Canadá. Anais... Louiseville: PSA, 1995. v.7, p.13.
MOODY, M.W. et al. Alligator meat: yelds, quality studied. Lousiania Agricola, v.24. n.1, p.14-15, 1980.

MORO, M.E.G. Análise citogenética e alguns aspectos produtivos da espécie Rhynchotus rufescens- Perdiz (Aves: Tinamidae). 1991. 97f. Dissertação (Mestrado em Zootecnia) - Curso de Pós-graduação Melhoramento Genético Animal Faculdade de Ciências Agrárias e Veterinárias, Universidade Estadual Paulista, Jaboticabal.

NATIONAL RESEARCH COUNCIL. Nutrient requeriments of poultry. 9.ed. Washington, National Academy of Science, 1994. 155p.

RAO, R.D. et al. Effect of weaning and slaughter on rabbit meat production. II. Carcass quality and composition. Journal Animal Science, v.46, n.3, p.576-583, 1978.

RODRIGUES, K.F. Avaliação do rendimento, da composição química e das qualidades sensoriais de carcaças comerciais de frangos. 1994. 70f. Dissertação (Mestrado em Produção de Aves) - Escola Superior de Agricultura de Lavras.

ROMANELLI, P.F. Propriedades tecnológicas da carne do jacaré do pantanal Caiman crocodilus yacare (DAUDIN, 1802) (Reptilia Crocodilia). 1995. 139f. Tese (Doutorado em Tecnologia de Alimentos) - Faculdade de Engenharia de Alimentos, Universidade de Campinas.

SAUVER, B.; PLOUZEAU, M. Technical and economical aspects of guinea fowl production in the world. Nouzilly, France: Station de Reserches Avicoles, INRA, 1993. p.319323.

SHANAWANY, M.M. Emergence of ostrich meat. In: MEAT INTERNATIONAL, 6., 1996, Hong Kong. Anais... Hong Kong, 1996. V.6, n.2, p.10-13.

TURGUT, H. Emulsifying capacity and stability of goat waterbufallo, sheep, and cattle muscle proteins. Journal Food Science. v.49, p.168-182, 1984.

WEEKS, S.E. The behavior of the red-winged tinamou, Rhynchotus rufescens. Zoologica, New York, v.58, n.1, p.1340, 1973 .

WHITING, R.C.; JENKINS, R.K. Comparison of rabbit beef and chicken meats for functional properies and frankfurter processing. J ournal Food Science, v.46, p.169-196, 1981. 